\title{
Neurological symptoms, manifestations, and complications associated with severe acute respiratory syndrome coronavirus 2 (SARS-CoV-2) and coronavirus disease 19 (COVID-19)
}

\author{
Biyan Nathanael Harapan ${ }^{1,2} \cdot$ Hyeon Joo Yoo ${ }^{3,4}$
}

Received: 25 September 2020 / Revised: 9 January 2021 / Accepted: 12 January 2021 / Published online: 23 January 2021

(c) Springer-Verlag GmbH Germany, part of Springer Nature 2021

\begin{abstract}
Severe acute respiratory syndrome coronavirus 2 (SARS-CoV-2), a novel coronavirus, is responsible for the outbreak of coronavirus disease 19 (COVID-19) and was first identified in Wuhan, China in December 2019. It is evident that the COVID-19 pandemic has become a challenging world issue. Although most COVID-19 patients primarily develop respiratory symptoms, an increasing number of neurological symptoms and manifestations associated with COVID-19 have been observed. In this narrative review, we elaborate on proposed neurotropic mechanisms and various neurological symptoms, manifestations, and complications of COVID-19 reported in the present literature. For this purpose, a review of all current published literature (studies, case reports, case series, reviews, editorials, and other articles) was conducted and neurological sequelae of COVID-19 were summarized. Essential and common neurological symptoms including gustatory and olfactory dysfunctions, myalgia, headache, altered mental status, confusion, delirium, and dizziness are presented separately in sections. Moreover, neurological manifestations and complications that are of great concern such as stroke, cerebral (sinus) venous thrombosis, seizures, meningoencephalitis, Guillain-Barré syndrome, Miller Fisher syndrome, acute myelitis, and posterior reversible encephalopathy syndrome (PRES) are also addressed systematically. Future studies that examine the impact of neurological symptoms and manifestations on the course of the disease are needed to further clarify and assess the link between neurological complications and the clinical outcome of patients with COVID-19. To limit long-term consequences, it is crucial that healthcare professionals can early detect possible neurological symptoms and are well versed in the increasingly common neurological manifestations and complications of COVID-19.
\end{abstract}

Keywords COVID-19 · SARS-CoV-2 · Central nervous system · Neurological symptoms · Neurological manifestations · Neurological complications

Biyan Nathanael Harapan

biyan.harapan@gmail.com;

biyan.harapan@med.uni-muenchen.de

1 Department of Neurosurgery, University Hospital, LudwigMaximilians-University of Munich, Marchionistr. 15, 81377 Munich, Germany

2 Department of Neuropathology, Leipzig University Hospital, Leipzig, Germany

3 Department of Radiotherapy and Radiation Oncology, University Hospital, Ludwig-Maximilians-University of Munich, Munich, Germany

4 Department of Neurosurgery, Heidelberg University Hospital, Heidelberg, Germany

\section{Introduction}

On March 11, 2020, the World Health Organization (WHO) declared the coronavirus disease 2019 (COVID-19) to be a world pandemic. COVID-19 is caused by the recently identified severe acute respiratory distress syndrome coronavirus 2 (SARS-CoV-2) and is an ongoing global health emergency [1]. As of January 10, 2021, there are 90.08 million confirmed cases of COVID-19 globally in 218 countries and over 1.93 million deaths (https://www.worldometers.info/ coronavirus/). Among all closed cases, 64.46 million subjects have recovered throughout the world, pointing to a recovery rate of around $97 \%$.

Most patients with COVID-19 present with mild respiratory illness such as dry cough, fever, and dyspnea. However, various neurological manifestations have also been 
associated with COVID-19 at presentation or in the course of the disease [2]. At least one subjective neurological symptom has been reported in over $90 \%$ of patients with COVID19 , which highlights the importance of subsequent neurological implications of the disease [3]. Headache, confusion, and dizziness are the most common general non-specific neurological symptoms observed in COVID-19 patients [4]. Furthermore, numerous studies have reported neurological complications of SARS-CoV-2 infection that have a potentially detrimental effect on the outcome of patients with COVID-19 [5]. Based on the available literature, patients with severe COVID-19 infection tend to develop more neurological abnormalities in comparison to those with mild infection [6].

This narrative review aims to outline the current knowledge on existing neurological symptoms, manifestations, and complications in COVID-19 patients.

\section{Methods}

We searched the PubMed database for articles in English, Spanish or German published until December 27, 2020. Different key words related to COVID-19 and neurological symptoms, manifestations and complications in titles and abstracts were used ("Neurology", "Neurological symptoms", "Neurological manifestations", "Neurological complications", "Neuro", "COVID-19", "SARS-CoV-2", "Headache", "Dizziness", "Hyposmia", "Anosmia", "Meningitis", "Encephalitis", "Encephalopathy", "Myalgia", "Seizure", "Epilepsy", "Stroke", "Ischemia", "Ataxia", "Myelitis", "PRES").

All relevant publications were independently screened by both authors (BNH and HJY) in their entirety to determine eligibility for inclusion. Apart from studies with a conclusive outcome, editorials, commentaries, case reports, case series, opinion letters, and viewpoints were considered in this review to fully exploit the potential offered by current literature. Exclusion was mainly based on topic, e.g. if the full text article did not primarily focus on a neurological symptom, manifestation, or complication of COVID-19. Results are reported in a narrative manner and divided into different sections within the text of this review.

\section{Results}

\section{Proposed neurotropic mechanisms of COVID-19 leading to neuropathology}

Moriguchi and colleagues first reported the presence of SARS-CoV-2 RNA in the cerebrospinal fluid (CSF) of a patient with encephalopathy and COVID-19 using real-time reverse transcription PCR (RT-PCR) [7]. Although further cases have since been reported [8-10], SARS-CoV-2 was not detected in the CSF of most COVID-19 patients with neurological manifestations $[11,12]$. There are three theoretical explanations for this finding. First of all, the virus is mainly cell-bound and spreads from cell to cell without invading the CSF. Second, CSF sampling requires a certain limit of detection, which the virus barely reaches despite its presence. Finally, the presence of haem products in CSF could interfere with the role of polymerase for detection of SARS-CoV-2.

Neurological symptoms and manifestations can affect three different systems: the central nervous system (CNS), the peripheral nervous system (PNS), and the musculoskeletal system [13]. Several hypotheses describe the possible mechanisms of action causing the neurological symptoms of COVID-19. SARS-CoV-2 seems to have different mechanisms that allow the virus to enter and damage the CNS: systemic hematogenous spread or neuronal retrograde dissemination. These two potential neurotropic mechanisms of SARS-CoV-2 involve the compromise of the blood brain barrier causing neuronal cell death due to viremia on the one hand and the entry of SARS-CoV-2 through the olfactory bulb and subsequent transport to neurons of the brain on the other hand [14]. Although the neuroinvasiveness of SARSCoV-2 has not yet been fully understood, multiple lines of evidence implicate that both hematogenous and neuronal route can be utilized to penetrate the CNS $[15,16]$.

The first mechanism relies on angiotensin-converting enzyme 2 (ACE 2) as the functional receptor for SARSCoV-2. The virus' spike protein interacts with ACE 2 receptors expressed in neurons and glial cells of the brain, which makes the brain susceptible for neuroinvasion. After binding to the ACE 2 receptor, the transmembrane protease serine 2 (TMPRSS2) leads to proteolytic cleavage and priming of the spike protein which allows the virus to gain entry into the host cells [16]. In humans, ACE 2 receptors are widely expressed in airway epithelia, kidney cells, small intestine, lung parenchyma, vascular endothelium and throughout the CNS including neurons, astrocytes, oligodendrocytes, substantia nigra, ventricles, middle temporal gyrus, posterior cingulate cortex and olfactory bulb [17]. SARS-CoV-2 has, therefore, the potential to infect neurons and glial cells expressed throughout the CNS.

After infecting the airways, SARS-CoV-2 can pass through the epithelial barrier and gain access to the bloodstream via infection of endothelial cells of the blood brain barrier or blood-CSF barrier in the choroid plexus. SARSCoV-2 can, moreover, infect leukocytes, which disseminate towards other tissues in the human body and then cross the barrier to gain access to the CNS; referred to as a Trojan horse mechanism [16]. Leukocytes release pro-inflammatory cytokines including TNF, which damages oligodendrocytes 
and neurons. They produce chemokines such as CCL5, CXCL10, and CXCL11 that induce chemoattraction of activated T cells. Astrocytes release chemokines such as CCL2, CCL5 and CXCL12, which serve to recruit more infected leukocytes. On the whole, we think that many more factors are involved in the inflammatory process and that SARS$\mathrm{CoV}-2$ ultimately initiates a vicious circle of neuroinflammation [15].

The second neuropathological pathway describes the invasion of the brain via the olfactory bulb and the upper nasal transcribial route by which SARS-CoV-2 spreads transneuronally to different zones of the brain.

Notably, several viruses can also infect and migrate through peripheral nerves to reach the CNS [18]. Regardless of which transmission route the virus takes advantage of, once the virus reaches the CNS, neurotropism and the subsequent immune response will cause a CNS pathology, resulting in a disease. Due to the high expression of ACE 2 in the gastrointestinal system, a fecal-oral pathway has further been hypothesized as a potential transmission pathway of SARS-CoV-2 [19]. Moreover, indirect immune-mediated CNS damage through cytokine storm is another possible neuropathological mechanism observed in COVID-19 patients [20]. Present literature on neuropathological alterations associated with COVID-19 is scarce. Evidence for COVID-19 infection involving direct neurotropism is limited, whereas hypoxia-associated neuropathological features that suggest a defect in microcirculation has been shown in an autopsy study [21].

\section{Neurological symptoms}

Interestingly, neurological symptoms and conditions may precede typical respiratory symptoms by several days or were even the only indicators of SARS-CoV-2 infection in otherwise asymptomatic COVID-19 carriers. Due to limited data, this information cannot be specified for each symptom/ manifestation separately.

Current literature suggests that neurological symptoms and manifestations resulting from COVID-19 can occur prior, during, and even after respiratory involvement [22].

\section{Gustatory and olfactory dysfunctions/taste and smell (hyposmia/anosmia) impairment}

Gustatory and olfactory disorders are the most common sudden neurologic symptoms of COVID-19 associated with the involvement of the PNS, which seem to develop in the early stages of the disease and is thus considered as useful diagnostic markers [23].

Preliminary reports implicate that olfactory sensory neurons do not express ACE 2, which prevent SARS-CoV-2 from infecting these cells. However, cells in the olfactory epithelium do express ACE 2 and are consequently vulnerable to SARS-CoV-2 infection. Damage to the olfactory epithelium rather than neuronal injury seems to be the cause of anosmia $[24,25]$.

In a systematic meta-analysis, the pooled prevalence for taste disturbances has been estimated at around $38.5 \%$ and $35.8 \%$ for smell disturbances [26]. Of note, several studies report a much higher incidence of taste and smell disturbances. For instance, out of 417 COVID-19 patients who participated in a multicenter European study, $85.6 \%$ had decreased smell function related to the infection, while $88.0 \%$ of the patients reported gustatory disorders characterized by impairment of different taste modalities. A significant positive association between olfactory and gustatory dysfunctions has been observed. The same study hints at a recovery rate of approximately $25.5 \%$ for both olfactory and gustatory functions throughout the 2 weeks after the resolution of typical respiratory symptoms [27].

In a study of Qiu et al., 10\% of COVID-19 patients had only olfactory or gustatory symptoms, and $19 \%$ had olfactory and/or gustatory complaints prior to any other COVID19 symptom.

Moreover, 25\% of children had only olfactory or gustatory symptoms at COVID-19 presentation, indicating that olfactory or gustatory disorders are possible early identifiers of COVID-19 and, therefore, has important implications for patient screening and disease control [28]. Further evaluation of olfactory function in COVID-19 patients that indicate a high prevalence of olfactory disorders has been carried out on hospitalized and non-hospitalized patients [29, 30]. Unsurprisingly, olfactory dysfunction has been suggested as a biomarker for COVID-19 and smell testing may help the early detection of COVID-19 patients who need early treatment or quarantine as a part of preventive measures aimed at controlling the spread of COVID-19 [31].

\section{Myalgia}

Myalgia is a common symptom observed in COVID-19 patients. The prevalence of myalgia greatly varies between studies, ranging from $3.36 \%$ to over $64 \%$ [32] with an estimated pooled prevalence of around 19.3\% [26]. It has been proposed that generalized inflammation and cytokine storm could be the pathophysiological background of myalgia [33]. At present, it is still uncertain whether muscle manifestation of COVID-19 is due to an unspecific systemic inflammation or direct muscle invasion. Elevated levels of lactate dehydrogenase and creatine kinase can be observed in patients with severe COVID-19 disease. Interestingly, present literature suggests that myalgia is not necessarily related to severe cases of COVID-19 and its mere presence is, therefore, not a reliable prognostic factor for severe COVID-19 disease [34]. 


\section{Headache}

Headache has been reported to be the most common nonspecific neurological symptom in a series of studies. The prevalence of headache varies depending on the studies' number of cases. For instance, some authors observe that around 6\% [35, 36] and 8\% [37] of all COVID-19 patients presented with headache, while others propose a much higher prevalence at around 20\% [38] and 25\% [39]. 14.7\% is the estimated pooled prevalence of this symptom [26]. Headache was frequently observed at the time of admission. Studies suggest that after fever, cough, myalgia/fatigue and dyspnea, headache is the fifth most frequent symptom of COVID-19 [37, 40, 41]. A personal clinical case written from the perspective of a neurologist, specifically a headache expert, shows that the headache associated with COVID-19 can be classified into two phases. While the headache in the initial phase, among others, included a diffuse pain, moderate in intensity that is attributed to systemic viral infection, the headache after 7-10 days was accompanied by photophobia and neck stiffness and is provoked by cytokine storm [42]. Other authors reported moderate-severe bilateral headache with pulsating or pressing quality in the temporoparietal, forehead, or periorbital region which is exacerbated when bending over [43]. As a non-specific symptom, headache might be interpreted as a random association to COVID-19; however, there is clear evidence that COVID19 patients who had never suffered from recurrent headache before, suddenly experience persistent disabling daily headache due to SARS-CoV-2 infection [44]. The onset of a new daily headache in subjects without previous personal headache history suggests a causal relation between headache and COVID-19 with severe pain more often presenting as a prodromal symptom. Headache has further been described as the first COVID-19 symptom in some cases [45].

\section{Altered mental status/confusion/delirium}

A case study from England indicates that acute confusion/ delirium can be a primary manifestation and the only presenting symptom of COVID-19 without overt respiratory symptoms [46]. A Chinese study estimates the prevalence of confusion at around 9\% [4], which coincides with the pooled prevalence of disturbances in consciousness/altered mental status of around 9.6\% [26].

Primary neuroinvasive hypotheses include the ability of SARS-CoV-2 to access the CNS directly via invasion of the olfactory bulb and secondary systemic mechanisms such as inflammatory cytokines, hypoxemia, and oxidative stress that are caused by ARDS (acute respiratory distress syndrome). These result in primary and secondary encephalopathy, respectively.
Other authors acknowledge delirium as a complication of COVID-19 and state that the presence of comorbidities found during the SARS-CoV-2 infection may facilitate the onset of an acute confusional state [47]. Independent of the etiology of delirium, hospitals should consider adding mental status changes to the list of testing criteria since delirium may be the only presenting symptom [48].

\section{Dizziness}

The prevalence of dizziness is estimated at around 8\% [49] to $9 \%$ [50], which corresponds to the overall pooled prevalence of dizziness at $8.77 \%$ in a systemic review regarding neurological characteristics of COVID-19 patients [51]. A retrospective, observational case series even describes dizziness to be the leading neurologic finding even before headache [6]. Of note, a case report shows a COVID-19 patient with a sudden onset of dizziness and dry throat with no other accompanying typical symptoms such as fever, cough, and headache [52]. Although dizziness seems to be unrelated to COVID-19 at first sight, clinicians should be vigilant about this neurological symptom as it may be caused by COVID-19, especially in the absence of common respiratory symptoms.

\section{Neurological manifestations and complications}

Among the studies conducted within a hospital network in Chicago, Illinois, neurologic manifestations were identified in about $42 \%$ at COVID-19 onset, in $63 \%$ at hospitalization and in $82 \%$ at any time during the course of the disease [53]. Similar findings were obtained in $36 \%$ of hospitalized COVID-19 patients in China and in around 60\% of COVID19 patients in Europe [6,54]. The differences in frequencies seem to rely on genetic factors such as ACE 2 receptor polymorphism as well as SARS-CoV-2 strain variations [55]. Recent literature indicates higher rates of mortality in COVID-19 patients with pre-existing chronic neurological disorders [56].

Biological and clinical observations suggest that SARSCoV-2 may be responsible for many neurological manifestations, which can be spilt into three main categories based on the following presumed underlying mechanisms. The first mechanism includes neurological consequences of pulmonary disease and associated systemic disease such as systemic inflammatory response syndrome, sepsis, and multiorgan failure. Encephalopathy and stroke can be assigned to this category. The second mechanism involves neurological manifestations that result from direct invasion of the CNS by the virus (e.g. encephalitis). Post-infectious, immunemediated complications such as GBS and its variants represent the last mechanism. As SARS-CoV-2 continues to spread across the world, our knowledge and understanding 
of neurological manifestations in patients is constantly evolving.

\section{Cerebrovascular diseases}

Stroke The acute ischemic stroke incidence among COVID19 patients is estimated at $2.3 \%$ with a pooled prevalence for acute cerebrovascular disease of $2.6 \%$ [26]; the prevalence of acute cerebrovascular diseases in hospitalized COVID-19 patients with more severe infection almost reaches 6\% [6]. Most of these cases presented with arterial stroke. A possible explanation for the occurrence of coagulation disorders in COVID-19 patients is the enhanced thrombus formation under conditions of hypoxia.

SARS-CoV-2 can infect endothelial cells resulting in endothelial dysfunction and arterial as well as venous micro- and macrovascular complications [57, 58]. Local inflammation and a vasculitic process in cerebral arterial walls are induced. Inflammation and apoptosis of endothelial cells after SARS-CoV-2 infection has recently been reported at autopsy in the lung, kidney, heart, and bowel [59]. The permeability of blood brain barrier might be increased via inflammatory cells accumulating in the vascular wall [57].

Viral infections are believed to stimulate and initiate a coagulation cascade, while complex cross-reactions occur between coagulative hemostasis and inflammation. COVID19 particularly causes sepsis-induced coagulopathy, which is characterized by elevated prothrombin time, elevated levels of D-dimer and thrombocytopenia without hypofibrinogenemia [60]. A downregulation of natural anticoagulant mechanisms due to inflammatory mediators and disruption of the coagulation system is involved in the pathophysiology. Generally, hypercoagulability is a major contributor to COVID-19-related complications and can be the cause of consecutive thromboembolic events in both the arterial and venous vascular beds [61]. Consequently, it is reasonable to perform laboratory monitoring of coagulation markers such as fibrinogen levels, D-dimer and markers of inflammation such as CRP and IL-6 levels to determine an underlying prothrombotic or inflammatory response, potentially helping to guide treatment [62]. Despite thromboprophylaxis, there seems to be a high cumulative incidence of thrombotic complications in critically ill COVID-19 patients, especially in those with pneumonia [63]. On the other hand, several findings suggest that ischemic cerebrovascular disease may simultaneously develop in the course of COVID-19 independently of a critical disease process [64].

There is a hint that COVID-19 patients have more severe anterior circulation large vessel occlusion strokes with a higher rate of multivessel occlusion and higher infarct core volume than control patients [65]. Thus, this neurological complication provides an explanation why COVID-19 leads to very poor outcome in some individuals $[66,67]$.
Cerebral venous (sinus) thrombosis Although an underestimation cannot be excluded, cerebral venous thrombosis is a rather rare complication (pooled prevalence of $0.3 \%$ [26]). Patients without any antecedent risk factors for cerebral venous thrombosis may develop this neurological sequela due to the prothrombotic state triggered by COVID-19 [6870]. Initial symptoms may include signs of increased intracranial pressure (ICP) such as progressive headache, visual problems, papilledema, focal neurologic deficits, decreased consciousness, and seizures [71]. The diagnosis of deep cerebral vein thrombosis can even be complicated by hemorrhagic venous infarction with large necrotic areas. Cerebral venous sinus thrombosis is primarily diagnosed based on clinical and radiological criteria with magnetic resonance imaging (MRI) and venography and computed tomographic venography being the non-invasive imaging modalities of choice [72]. Treatment with heparin anticoagulation is favored, either with therapeutic doses of low molecular weight heparin (LMWH) or unfractionated heparin (UFH). Based on currently available evidence, LMWH seems to be more effective than UFH with lower rates of mortality, and hence LMWH is recommended as the first-line therapy if there is no other contraindication $[73,74]$.

\section{Epilepsy and seizures}

With increasing case reports regarding COVID-19 patients presenting with seizures, current literature suggests that COVID-19 can reduce seizure threshold in patients with an existing seizure disorder. What is more, COVID-19 does not only worsen seizure control in patients with previously wellcontrolled seizures, but it can trigger new-onset seizures in patients with no known history of seizures [75-79]. Direct effects of COVID-19 on patients with epilepsy and the exact prevalence of new-onset epilepsy cases is still unclear (estimated pooled prevalence $0.9 \%$ [26]). Hypoxia, fever, multiorgan failure, and severe metabolic or electrolyte disarrangements due to COVID-19 can possibly trigger seizures [80]. Seizure can also occur secondary to a meningitis/encephalitis associated with SARS-CoV-2 infection [7]. Furthermore, seizures can be the initial presentation of COVID-19 and patients may have no respiratory symptoms at all [81]. Apart from generalized tonic-clonic seizures, focal seizures have also been observed as a clinical feature of COVID-19 [82]. Pediatric seizure cases have been reported and therefore, seizure must be recognized as a potential COVID-19 presentation in the pediatric age groups, even in children without fever (afebrile seizures) [83, 84]. In addition to antiepileptic drugs, patients who severely suffer from COVID-19 and further demonstrate clinical signs of seizures or encephalopathy could benefit from electroencephalography monitoring to early diagnose and treat seizures [85]. Despite the lack of clear evidence suggesting an additional risk of symptomatic 
seizures in COVID-19 patients [86], uncommon and atypical clinal presentation of COVID-19 patients in association with seizure must be considered to prevent complications and long-term sequelae.

\section{Meningitis, encephalitis, and meningoencephalitis}

Several case reports' findings of patients with COVID-19 are suggestive of meningitis and encephalitis. COVID-19 patients can initially complain of headache, fever, and a new-onset seizure [7, 87]. In some COVID-19 patients, the presence of SARS-CoV-2 was found in the CSF, confirming that this neurological manifestation is to be attributed to the virus [7, 9, 88]. However, COVID-19 patients presenting with acute meningoencephalitis with neither SARS-CoV-2 nor other viral pathogens detected in the CSF have also been observed $[89,90]$. Therefore, undetectable SARS-CoV-2RNA in the CSF may indicate that other than direct brain infection might be responsible for meningoencephalitis, e.g. peri-infectious inflammation and altered neurotransmission. COVID-19 patients' CSF may reveal lymphocytic pleocytosis $[87,89]$. Since meningoencephalitis can be complicated by intracerebral und subdural hematomas, early detection is essential to provide appropriate treatment and prevent hemorrhagic encephalopathy that can lead to severe invalidity or threaten the patient's life. Due to the detrimental consequences, physicians should always be aware of this possible manifestation [91].

\section{Guillain-Barré syndrome (GBS)}

As an inflammatory polyradiculoneuropathy associated with numerous infections (e.g. Campylobacter jejuni, Epstein-Barr virus, cytomegalovirus), COVID-19 patients with GBS can present with various neurological symptoms. For instance, lower limb weakness and paresthesia that may lead to generalized tetraparesis or tetraplegia evolving over a period of several days have been repeatedly observed [92]. Typically, MRI performed with the administration of gadolinium reveals enhancement of the cauda equina nerve roots on postcontrast findings and asymmetrical thickening and hyperintensity of postganglionic roots of the brachial and lumbar plexuses [93, 94]. Moreover, cytoalbuminologic dissociation of the CSF is a characteristic finding in GBS, pointing to nerve root involvement. Analysis of CSF usually reveals normal white cell count and increased protein concentrations $[95,96]$. Results of electrophysiological studies are frequently consistent with a demyelinating polyradiculoneuropathy and/or axonal damage. Of note, it seems that most COVID-19 patients who suffer from GBS predominantly presented with a demyelinating electrophysiological subtype (acute inflammatory demyelinating polyneuropathy) [97, 98]. Generally, GBS shows a good response to intravenous immunoglobulin treatment with significant neurological improvement, suggesting an immune-mediated nature of neuropathy $[99,100]$.

\section{Miller Fisher syndrome (MFS)}

MFS is classified as a variant of GBS and characterized by a triad of ophthalmoplegia, ataxia, and areflexia [101]. Comparable to GBS, symptoms may be preceded by a viral infection. This neurological complication is frequently associated with anti-GQ1b antibodies detected in serum samples from MFS patients, although several case reports noted negative antiganglioside antibodies [102-104]. Negative antibody testing in COVID-19 patients with MFS may signal that symptoms are caused by viral neurotropism and not immune-mediated injury [105]. Similar to the treatment of GBS, intravenous immunoglobulin usually results in subsequent improvement of neurologic symptoms [104, 106].

\section{Acute myelitis}

Several cases of COVID-19 patients with transverse myelitis have been observed during the ongoing COVID-19 pandemic. Paresthesia and hypoesthesia of the feet progressing to the abdominal area may be the first symptoms of myelitis. This can result in weakness of the lower limbs that can rapidly progress to paraplegia with total anesthesia below a certain spinal cord level and eventually sphincter incontinence [107]. Apart from transverse myelitis that is caused by COVID-19, the differential diagnosis of acute-onset ascending symmetric paraplegia that must be considered include acute inflammatory demyelinating polyradiculoneuropathy (GBS), traumatic spinal injury, epidural hematoma and/or abscess, post-diphtheric polyneuropathy, acute intermittent porphyria, periodic paralysis and paralytic poliomyelitis [108]. An aberrant immune response and immune-mediated pathogenesis are possible explanations for myelitis in COVID-19 patients. MRI is the most frequently used imaging modality for the diagnosis of suspected cases of acute myelitis since it does not only indicate spinal cord lesions but also excludes other possible pathologies that may present with similar clinical symptoms [109]. Neurologic improvement can be achieved through immunomodulatory treatment such as steroids and plasmapheresis [110]. For instance, corticosteroid therapy such as intravenous methylprednisolone $1 \mathrm{~g}$ per day for 3 days may rapidly improve neurological symptoms [111].

\section{Posterior reversible encephalopathy syndrome (PRES)}

Clinical features of this disease can, among others, include non-specific symptoms such as headache, altered consciousness, visual disturbances, seizures, and fluctuations 
in blood pressure. PRES may result from elevated inflammatory markers and cytokines leading to changes in endothelial morphology, impairment of the blood-brain barrier and consecutive increased vascular permeability [112]. MRI of the brain typically indicates cerebral vasogenic edema in the parietal and occipital regions bilaterally, occasionally associated with hemorrhagic lesions [113]. Patients with severe SARS-CoV-2 infection have a drastic inflammatory reaction, provoking a cytokine storm which damages the blood brain barrier and resulting in PRES. The associated hemorrhage seen in several COVID19 patients $[114,115]$ can be explained by coagulopathy and both thrombotic and hemorrhagic pathologies of severe SARS-CoV-2 infection. As a rather rare neurological condition, it seems unlikely that the occurrence of this disorder in COVID-19 patients is completely unrelated to SARS-CoV-2 infection, especially since there are signs of increased cases of PRES in the context of the COVID-19 pandemic (e.g. higher weekly average cases of PRES than over the past 5 years [116]).

(Table 1 is a summary on neurological symptoms, manifestations, and complications mentioned in the present literature, including those with scarce detailed report or insufficient data).

\section{Conclusions}

At present, most publications focus on the general clinical presentation and common respiratory aspects of COVID19, whereas our review highlights the nervous system involvement of SARS-CoV-2 infection with respect to its diverse neurological presentation. Since most reports and studies mainly put emphasis on respiratory symptoms, the prevalence of neurological sequalae of COVID-19 might be underestimated. Many neurological symptoms and manifestations have been reported in several COVID-19 cases, however, insufficient data restricts detailed description of these symptoms' prevalence and characteristics. From the available data, we conclude that non-specific neurological symptoms may indicate a SARS-CoV-2 infection and thus, clinicians should always be vigilant for neurological manifestations and detect them at an early stage to prevent inappropriate management of COVID-19 patients and address
Table 1 Neurological symptoms, manifestations, and complications in association with COVID-19

\begin{tabular}{ll}
\hline Neurological symptoms & Neurological manifestations and complications \\
\hline Gustatory dysfunctions (38.5\%) & Stroke (2.3\%) \\
Olfactory dysfunctions (hyposmia/anosmia) & Epilepsy and seizures (0.9\%) \\
$\quad(35.8 \%)$ & \\
Myalgia (19.3\%) & Cerebral venous (sinus) thrombosis (0.3\%) \\
Headache (14.7\%) & Meningitis, encephalitis, meningoencephalitis \\
Altered mental status (9.4\%) [5, 117] & Guillan-Barré syndrome \\
Dizziness (8.77\%) & Miller Fisher syndrome/Bickerstaff's encephalitis [118] \\
Nausea and vomiting (4.6\%) [51,119] & Acute myelitis \\
Neuralgia (2.3\%) [32, 120] & Posterior reversible encephalopathy syndrome (PRES) \\
Ataxia (0.3\%) [121, 122] & Acute hemorrhagic necrotizing encephalopathy [123, 124] \\
Myoclonus [125, 126] & Acute demyelinating encephalomyelitis (ADEM)-like \\
& pathology [127, 128] \\
Diplopia [129] & Posthypoxic necrotizing leukoencephalopathy [130] \\
Vision loss [131] & CNS vasculitis [117] \\
Stupor [2] & Acute cerebellitis [132] \\
Meningism [133] & Movement disorders [134] \\
Dysexecutive syndrome [135] & Intensive-care-unit acquired neuropathy [2] \\
Bilateral leg stiffening [136] & Rhabdomyolysis [137] \\
Sustained upward gaze [136] & Critical illness myopathy [138, 139] \\
& Necrotizing autoimmune myositis (NAM) [140] \\
& Acute mesenteric ischemia [141] \\
\hline
\end{tabular}

This table summarizes different neurological symptoms, manifestations, and complications observed in association with COVID-19. Symptoms, manifestations, and complications written in bold are each addressed separately in the manuscript. All other symptoms, manifestations, and complications have been reported or at least mentioned in articles regarding COVID-19; however, insufficient data restrict detailed information.

The percentage in parentheses indicates the prevalence of the neurological symptom/manifestation/complication. 
neurological complications adequately. Noteworthily, patients with severe COVID-19 infection are more prone to develop neurological complications than nonsevere patients.

We hope that this review article allows healthcare professionals to be aware of the heterogenous neurological symptoms and manifestations of COVID-19 when dealing with the current viral pandemic. Clinicians must be alert to potential neurological complications during the diagnosis and treatment of patients with COVID-19 to reduce patient morbidity and mortality. Further studies are warranted to identify the broad spectrum of neurological symptoms, manifestations, and complications of COVID-19 and the underlying pathophysiological mechanisms.

Author contributions BNH: idea for the article, screening of relevant publications, data acquisition, analysis and interpretation of data, drafting and revising the manuscript, approving the final draft. HJY: screening of relevant publications, interpretation of data, revising and editing the manuscript, approving the final draft.

Funding Open Access funding enabled and organized by Projekt DEAL..

Data availability Authors can confirm that all relevant data are included in the article. Dataset(s) derived from public resources and made available with the article (references).

\section{Compliance with ethical standards}

Conflict of interest On behalf of all authors, the corresponding author states that there is no conflict of interest.

\section{References}

1. Feng W, Zong W, Wang F, Ju S (2020) Severe acute respiratory syndrome coronavirus 2 (SARS-CoV-2): a review. Mol Cancer 19(1):100. https://doi.org/10.1186/s12943-020-01218-1

2. Tsivgoulis G, Palaiodimou L, Katsanos AH, Caso V, Köhrmann M, Molina C, Cordonnier C, Fischer U, Kelly P, Sharma VK, Chan AC, Zand R, Sarraj A, Schellinger PD, Voumvourakis KI, Grigoriadis N, Alexandrov AV, Tsiodras S (2020) Neurological manifestations and implications of COVID-19 pandemic. Ther Adv Neurol Disord. https://doi.org/10.1177/1756286420932036

3. Liguori C, Pierantozzi M, Spanetta M, Sarmati L, Cesta N, Iannetta M, Ora J, Mina GG, Puxeddu E, Balbi O, Pezzuto G, Magrini A, Rogliani P, Andreoni M, Mercuri NB (2020) Subjective neurological symptoms frequently occur in patients with SARS-CoV2 infection. Brain Behav Immun. https://doi. org/10.1016/j.bbi.2020.05.037

4. Chen N, Zhou M, Dong X, Qu J, Gong F, Han Y, Qiu Y, Wang J, Liu Y, Wei Y, Xia Ja YuT, Zhang X, Zhang L (2020) Epidemiological and clinical characteristics of 99 cases of 2019 novel coronavirus pneumonia in Wuhan, China: a descriptive study. Lancet 395(10223):507-513. https://doi.org/10.1016/s0140 $-6736(20) 30211-7$

5. Sheraton M, Deo N, Kashyap R, Surani S (2020) A review of neurological complications of COVID-19. Cureus 12(5):e8192. https://doi.org/10.7759/cureus.8192
6. Mao L, Jin H, Wang M, Hu Y, Chen S, He Q, Chang J, Hong C, Zhou Y, Wang D, Miao X, Li Y, Hu B (2020) Neurologic manifestations of hospitalized patients with coronavirus disease 2019 in Wuhan, China. JAMA Neurol. https://doi.org/10.1001/ jamaneurol.2020.1127

7. Moriguchi T, Harii N, Goto J, Harada D, Sugawara H, Takamino J, Ueno M, Sakata H, Kondo K, Myose N, Nakao A, Takeda M, Haro H, Inoue O, Suzuki-Inoue K, Kubokawa K, Ogihara S, Sasaki T, Kinouchi H, Kojin H, Ito M, Onishi H, Shimizu T, Sasaki Y, Enomoto N, Ishihara H, Furuya S, Yamamoto T, Shimada S (2020) A first case of meningitis/ encephalitis associated with SARS-Coronavirus-2. Int J Infect Dis 94:55-58. https://doi.org/10.1016/j.ijid.2020.03.062

8. Domingues RB, Mendes-Correa MC, de Moura Leite FBV, Sabino EC, Salarini DZ, Claro I, Santos DW, de Jesus JG, Ferreira NE, Romano CM, Soares CAS (2020) First case of SARS-COV-2 sequencing in cerebrospinal fluid of a patient with suspected demyelinating disease. J Neurol 267(11):31543156. https://doi.org/10.1007/s00415-020-09996-w

9. Huang YH, Jiang D, Huang JT (2020) SARS-CoV-2 detected in cerebrospinal fluid by PCR in a case of COVID-19 encephalitis. Brain Behav Immun 87:149. https://doi.org/10.1016/j. bbi.2020.05.012

10. Virhammar J, Kumlien E, Fallmar D, Frithiof R, Jackmann S, Skold MK, Kadir M, Frick J, Lindeberg J, Olivero-Reinius H, Ryttlefors M, Cunningham JL, Wikstrom J, Grabowska A, Bondeson K, Bergquist J, Zetterberg H, Rostami E (2020) Acute necrotizing encephalopathy with SARS-CoV-2 RNA confirmed in cerebrospinal fluid. Neurology 95(10):445-449. https://doi.org/10.1212/WNL.0000000000010250

11. Filatov A, Sharma P, Hindi F, Espinosa PS (2020) Neurological complications of coronavirus disease (COVID-19): encephalopathy. Cureus 12(3):e7352. https://doi.org/10.7759/cureu s.7352

12. Paniz-Mondolfi A, Bryce C, Grimes Z, Gordon RE, Reidy J, Lednicky J, Sordillo EM, Fowkes M (2020) Central nervous system involvement by severe acute respiratory syndrome coronavirus-2 (SARS-CoV-2). J Med Virol 92(7):699-702. https:// doi.org/10.1002/jmv. 25915

13. Leonardi M, Padovani A, McArthur JC (2020) Neurological manifestations associated with COVID-19: a review and a call for action. J Neurol. https://doi.org/10.1007/s00415-020-09896 $-\mathrm{Z}$

14. Zhou Z, Kang H, Li S, Zhao X (2020) Understanding the neurotropic characteristics of SARS-CoV-2: from neurological manifestations of COVID-19 to potential neurotropic mechanisms. J Neurol. https://doi.org/10.1007/s00415-020-09929-7

15. Desforges M, Le Coupanec A, Brison E, Meessen-Pinard M, Talbot PJ (2014) Neuroinvasive and neurotropic human respiratory coronaviruses: potential neurovirulent agents in humans. Adv Exp Med Biol 807:75-96. https://doi. org/10.1007/978-81-322-1777-0_6

16. Desforges M, Le Coupanec A, Dubeau P, Bourgouin A, Lajoie L, Dube M, Talbot PJ (2019) Human coronaviruses and other respiratory viruses: underestimated opportunistic pathogens of the central nervous system? Viruses. https://doi.org/10.3390/v1201 0014

17. Chen R, Wang K, Yu J, Chen Z, Wen C, Xu Z (2020) The spatial and cell-type distribution of SARS-CoV-2 receptor ACE2 in human and mouse brain. bioRxiv. https://doi. org/10.1101/2020.04.07.030650

18. Swanson PA 2nd, McGavern DB (2015) Viral diseases of the central nervous system. Curr Opin Virol 11:44-54. https://doi. org/10.1016/j.coviro.2014.12.009 
19. Amirian ES (2020) Potential fecal transmission of SARS-CoV-2: current evidence and implications for public health. Int J Infect Dis 95:363-370. https://doi.org/10.1016/j.ijid.2020.04.057

20. Ahmed MU, Hanif M, Ali MJ, Haider MA, Kherani D, Memon GM, Karim AH, Sattar A (2020) Neurological manifestations of COVID-19 (SARS-CoV-2): a review. Front Neurol. https://doi. org/10.3389/fneur.2020.00518

21. Kantonen J, Mahzabin S, Mayranpaa MI, Tynninen O, Paetau A, Andersson N, Sajantila A, Vapalahti O, Carpen O, Kekalainen E, Kantele A, Myllykangas L (2020) Neuropathologic features of four autopsied COVID-19 patients. Brain Pathol. https://doi. org/10.1111/bpa.12889

22. Keyhanian K, Umeton RP, Mohit B, Davoudi V, Hajighasemi F, Ghasemi M (2020) SARS-CoV-2 and nervous system: From pathogenesis to clinical manifestation. J Neuroimmunol 350:577436. https://doi.org/10.1016/j.jneuroim.2020.577436

23. Cooper KW, Brann DH, Farruggia MC, Bhutani S, Pellegrino R, Tsukahara T, Weinreb C, Joseph PV, Larson ED, Parma V, Albers MW, Barlow LA, Datta SR, Di Pizio A (2020) COVID19 and the chemical senses: supporting players take center stage. Neuron 107(2):219-233. https://doi.org/10.1016/j.neuro n.2020.06.032

24. Brann DH, Tsukahara T, Weinreb C, Lipovsek M, Van den Berge K, Gong B, Chance R, Macaulay IC, Chou HJ, Fletcher RB, Das D, Street K, de Bezieux HR, Choi YG, Risso D, Dudoit S, Purdom E, Mill J, Hachem RA, Matsunami H, Logan DW, Goldstein BJ, Grubb MS, Ngai J, Datta SR (2020) Non-neuronal expression of SARS-CoV-2 entry genes in the olfactory system suggests mechanisms underlying COVID-19-associated anosmia. Sci Adv. https://doi.org/10.1126/sciadv.abc5801

25. Fodoulian L, Tuberosa J, Rossier D, Landis BN, Carleton A, Rodriguez I (2020) SARS-CoV-2 receptor and entry genes are expressed by sustentacular cells in the human olfactory neuroepithelium. bioRxiv. https://doi.org/10.1101/2020.03.31.013268

26. Favas TT, Dev P, Chaurasia RN, Chakravarty K, Mishra R, Joshi D, Mishra VN, Kumar A, Singh VK, Pandey M, Pathak A (2020) Neurological manifestations of COVID-19: a systematic review and meta-analysis of proportions. Neurol Sci 41(12):3437-3470. https://doi.org/10.1007/s10072-020-04801-y

27. Lechien JR, Chiesa-Estomba CM, De Siati DR, Horoi M, Le Bon SD, Rodriguez A, Dequanter D, Blecic S, El Afia F, Distinguin L, Chekkoury-Idrissi Y, Hans S, Delgado IL, Calvo-Henriquez C, Lavigne P, Falanga C, Barillari MR, Cammaroto G, Khalife M, Leich P, Souchay C, Rossi C, Journe F, Hsieh J, Edjlali M, Carlier R, Ris L, Lovato A, De Filippis C, Coppee F, Fakhry N, Ayad T, Saussez S (2020) Olfactory and gustatory dysfunctions as a clinical presentation of mild-to-moderate forms of the coronavirus disease (COVID-19): a multicenter European study. Eur Arch Otorhinolaryngol. https://doi.org/10.1007/s00405-02005965-1

28. Qiu C, Cui C, Hautefort C, Haehner A, Zhao J, Yao Q, Zeng H, Nisenbaum EJ, Liu L, Zhao Y, Zhang D, Levine CG, Cejas I, Dai Q, Zeng M, Herman P, Jourdaine C, de With K, Draf J, Chen B, Jayaweera DT, Denneny JC 3rd, Casiano R, Yu H, Eshraghi AA, Hummel T, Liu X, Shu Y, Lu H (2020) Olfactory and gustatory dysfunction as an early identifier of COVID-19 in adults and children: an international multicenter study. Otolaryngol Head Neck Surg 163(4):714-721. https://doi.org/10.1177/0194599820 934376

29. Lechien JR, Cabaraux P, Chiesa-Estomba CM, Khalife M, Hans S, Calvo-Henriquez C, Martiny D, Journe F, Sowerby L, Saussez S (2020) Objective olfactory evaluation of self-reported loss of smell in a case series of 86 COVID-19 patients. Head Neck. https ://doi.org/10.1002/hed.26279

30. Tsivgoulis G, Fragkou PC, Delides A, Karofylakis E, Dimopoulou D, Sfikakis PP, Tsiodras S (2020) Quantitative evaluation of olfactory dysfunction in hospitalized patients with Coronavirus [2] (COVID-19). J Neurol. https://doi.org/10.1007/s00415-02009935-9

31. Moein ST, Hashemian SM, Mansourafshar B, Khorram-Tousi A, Tabarsi P, Doty RL (2020) Smell dysfunction: a biomarker for COVID-19. Int Forum Allergy Rhinol 10(8):944-950. https ://doi.org/10.1002/alr.22587

32. Tsai S-T, Lu M-K, San S, Tsai C-H (2020) The neurologic manifestations of coronavirus disease 2019 pandemic: a systemic review. Front Neurol. https://doi.org/10.3389/fneur .2020 .00498

33. Jiang X, Coffee M, Bari A, Wang J, Jiang X, Huang J, Shi J, Dai J, Cai J, Zhang T, Wu Z, He G, Huang Y (2020) Towards an artificial intelligence framework for data-driven prediction of coronavirus clinical severity. Comput Mater Contin 62(3):537-551. https://doi.org/10.32604/cmc.2020.010691

34. Lippi G, Wong J, Henry BM (2020) Myalgia may not be associated with severity of coronavirus disease 2019 (COVID-19). World J Emerg Med 11(3):193-194. https://doi.org/10.5847/ wjem.j.1920-8642.2020.03.013

35. Yang X, Yu Y, Xu J, Shu H, Ja X, Liu H, Wu Y, Zhang L, Yu Z, Fang M, Yu T, Wang Y, Pan S, Zou X, Yuan S, Shang Y (2020) Clinical course and outcomes of critically ill patients with SARS-CoV-2 pneumonia in Wuhan, China: a single-centered, retrospective, observational study. Lancet Respir Med 8(5):475-481. https://doi.org/10.1016/s2213-2600(20)30079 $-5$

36. Tian S, Hu N, Lou J, Chen K, Kang X, Xiang Z, Chen H, Wang D, Liu N, Liu D, Chen G, Zhang Y, Li D, Li J, Lian H, Niu S, Zhang L, Zhang J (2020) Characteristics of COVID-19 infection in Beijing. J Infect 80(4):401-406. https://doi.org/10.1016/j. jinf.2020.02.018

37. Huang C, Wang Y, Li X, Ren L, Zhao J, Hu Y, Zhang L, Fan G, Xu J, Gu X, Cheng Z, Yu T, Xia J, Wei Y, Wu W, Xie X, Yin W, Li H, Liu M, Xiao Y, Gao H, Guo L, Xie J, Wang G, Jiang R, Gao Z, Jin Q, Wang J, Cao B (2020) Clinical features of patients infected with 2019 novel coronavirus in Wuhan, China. Lancet 395(10223):497-506. https://doi.org/10.1016/s0140 $-6736(20) 30183-5$

38. Choi WS, Kang CI, Kim Y, Choi JP, Joh JS, Shin HS, Kim G, Peck KR, Chung DR, Kim HO, Song SH, Kim YR, Sohn KM, Jung Y, Bang JH, Kim NJ, Lee KS, Jeong HW, Rhee JY, Kim ES, Woo H, Oh WS, Huh K, Lee YH, Song JY, Lee J, Lee CS, Kim BN, Choi YH, Jeong SJ, Lee JS, Yoon JH, Wi YM, Joung MK, Park SY, Lee SH, Jung SI, Kim SW, Lee JH, Lee H, Ki HK, Kim YS, Korean Society of Infectious D (2016) Clinical presentation and outcomes of middle east respiratory syndrome in the Republic of Korea. Infect Chemother 48(2):118-126. https ://doi.org/10.3947/ic.2016.48.2.118

39. Kim ES, Chin BS, Kang CK, Kim NJ, Kang YM, Choi JP, Oh DH, Kim JH, Koh B, Kim SE, Yun NR, Lee JH, Kim JY, Kim Y, Bang JH, Song KH, Kim HB, Chung KH, Oh MD, Korea National Committee for Clinical Management of C (2020) Clinical course and outcomes of patients with severe acute respiratory syndrome coronavirus 2 infection: a preliminary report of the first 28 patients from the Korean Cohort Study on COVID19. J Korean Med Sci 35(13):e142. https://doi.org/10.3346/ jkms.2020.35.e142

40. Borge do Nascimento IJ, Cacic N, Abdulazeem HM, von Groote TC, Jayarajah U, Weerasekara I, Esfahani MA, Civile VT, Marusic A, Jeroncic A, Carvas Junior N, Pericic TP, Zakarija-Grkovic I, Meirelles Guimaraes SM, Luigi Bragazzi N, Bjorklund M, Sofi-Mahmudi A, Altujjar M, Tian M, Arcani DMC, O’Mathuna DP, Marcolino MS (2020) Novel coronavirus infection (COVID19) in humans: a scoping review and meta-analysis. J Clin Med. https://doi.org/10.3390/jcm9040941 
41. Lai CC, Shih TP, Ko WC, Tang HJ, Hsueh PR (2020) Severe acute respiratory syndrome coronavirus 2 (SARS-CoV-2) and coronavirus disease-2019 (COVID-19): The epidemic and the challenges. Int J Antimicrob Agents 55(3):105924. https://doi. org/10.1016/j.ijantimicag.2020.105924

42. Belvis R (2020) Headaches during COVID-19: my clinical case and review of the literature. Headache. https://doi.org/10.1111/ head.13841

43. Bolay H, Gul A, Baykan B (2020) COVID-19 is a real headache. Headache. https://doi.org/10.1111/head.13856

44. Caronna E, Ballve A, Llaurado A, Gallardo VJ, Ariton DM, Lallana S, Lopez Maza S, Olive Gadea M, Quibus L, Restrepo JL, Rodrigo-Gisbert M, Vilaseca A, Hernandez Gonzalez M, Martinez Gallo M, Alpuente A, Torres-Ferrus M, Pujol Borrell R, Alvarez-Sabin J, Pozo-Rosich P (2020) Headache: A striking prodromal and persistent symptom, predictive of COVID19 clinical evolution. Cephalalgia 40(13):1410-1421. https://doi. org/10.1177/0333102420965157

45. Singh J, Ali A (2020) Headache as the presenting symptom in 2 patients with COVID-19 and a history of migraine: 2 case reports. Headache 60(8):1773-1776. https://doi.org/10.1111/ head.13890

46. Butt I, Sawlani V, Geberhiwot T (2020) Prolonged Confusional state as first manifestation of COVID-19. Ann Clin Transl Neurol. https://doi.org/10.1002/acn3.51067

47. Cipriani G, Danti S, Nuti A, Carlesi C, Lucetti C, Di Fiorino M (2020) A complication of coronavirus disease 2019: delirium. Acta Neurol Belg 120(4):927-932. https://doi.org/10.1007/s1376 0-020-01401-7

48. Beach SR, Praschan NC, Hogan C, Dotson S, Merideth F, Kontos N, Fricchione GL, Smith FA (2020) Delirium in COVID-19: a case series and exploration of potential mechanisms for central nervous system involvement. Gen Hosp Psychiatry 65:47-53. https://doi.org/10.1016/j.genhosppsych.2020.05.008

49. Chen T, Wu D, Chen H, Yan W, Yang D, Chen G, Ma K, Xu D, Yu H, Wang H, Wang T, Guo W, Chen J, Ding C, Zhang X, Huang J, Han M, Li S, Luo X, Zhao J, Ning Q (2020) Clinical characteristics of 113 deceased patients with coronavirus disease 2019: retrospective study. BMJ 368:m1091. https://doi. org/10.1136/bmj.m1091

50. Wang D, Hu B, Hu C, Zhu F, Liu X, Zhang J, Wang B, Xiang H, Cheng Z, Xiong Y, Zhao Y, Li Y, Wang X, Peng Z (2020) Clinical characteristics of 138 hospitalized patients with 2019 novel coronavirus-infected pneumonia in Wuhan, China. JAMA. https ://doi.org/10.1001/jama.2020.1585

51. Pinzon RT, Wijaya VO, Buana RB, Al Jody A, Nunsio PN (2020) Neurologic characteristics in coronavirus disease 2019 (COVID19): a systematic review and meta-analysis. Front Neurol. https ://doi.org/10.3389/fneur.2020.00565

52. Kong Z, Wang J, Li T, Zhang Z, Jian J (2020) 2019 novel coronavirus pneumonia with onset of dizziness: a case report. Ann Transl Med 8(7):506. https://doi.org/10.21037/atm.2020.03.89

53. Liotta EM, Batra A, Clark JR, Shlobin NA, Hoffman SC, Orban ZS, Koralnik IJ (2020) Frequent neurologic manifestations and encephalopathy-associated morbidity in Covid-19 patients. Ann Clin Transl Neurol 7(11):2221-2230. https://doi.org/10.1002/ acn3.51210

54. Romero-Sanchez CM, Diaz-Maroto I, Fernandez-Diaz E, Sanchez-Larsen A, Layos-Romero A, Garcia-Garcia J, Gonzalez E, Redondo-Penas I, Perona-Moratalla AB, Del Valle-Perez JA, Gracia-Gil J, Rojas-Bartolome L, Feria-Vilar I, Monteagudo M, Palao M, Palazon-Garcia E, Alcahut-Rodriguez C, SopelanaGaray D, Moreno Y, Ahmad J, Segura T (2020) Neurologic manifestations in hospitalized patients with COVID-19: The
ALBACOVID registry. Neurology 95(8):e1060-e1070. https:// doi.org/10.1212/WNL.0000000000009937

55. Shen Z, Xiao Y, Kang L, Ma W, Shi L, Zhang L, Zhou Z, Yang J, Zhong J, Yang D, Guo L, Zhang G, Li H, Xu Y, Chen M, Gao Z, Wang J, Ren L, Li M (2020) Genomic diversity of severe acute respiratory syndrome-coronavirus 2 in patients with coronavirus disease 2019. Clin Infect Dis 71(15):713-720. https://doi. org/10.1093/cid/ciaa203

56. Garcia-Azorin D, Martinez-Pias E, Trigo J, Hernandez-Perez I, Valle-Penacoba G, Talavera B, Simon-Campo P, de Lera M, Chavarria-Miranda A, Lopez-Sanz C, Gutierrez-Sanchez M, Martinez-Velasco E, Pedraza M, Sierra A, Gomez-Vicente B, Guerrero A, Ezpeleta D, Penarrubia MJ, Gomez-Herreras JI, Bustamante-Munguira E, Abad-Molina C, Orduna-Domingo A, Ruiz-Martin G, Jimenez-Cuenca MI, Juarros S, Del PozoVegas C, Duenas-Gutierrez C, de Paula JMP, Canton-Alvarez B, Vicente JM, Arenillas JF (2020) Neurological comorbidity is a predictor of death in covid-19 disease: a cohort study on 576 patients. Front Neurol 11:781. https://doi.org/10.3389/fneur .2020 .00781

57. Pons S, Fodil S, Azoulay E, Zafrani L (2020) The vascular endothelium: the cornerstone of organ dysfunction in severe SARS-CoV-2 infection. Crit Care 24(1):353. https://doi. org/10.1186/s13054-020-03062-7

58. Klok FA, Kruip M, van der Meer NJM, Arbous MS, Gommers D, Kant KM, Kaptein FHJ, van Paassen J, Stals MAM, Huisman MV, Endeman H (2020) Incidence of thrombotic complications in critically ill ICU patients with COVID-19. Thromb Res 191:145-147. https://doi.org/10.1016/j.thromres.2020.04.013

59. Varga Z, Flammer AJ, Steiger P, Haberecker M, Andermatt R, Zinkernagel AS, Mehra MR, Schuepbach RA, Ruschitzka F, Moch H (2020) Endothelial cell infection and endotheliitis in COVID-19. Lancet 395(10234):1417-1418. https://doi. org/10.1016/s0140-6736(20)30937-5

60. Al-Ani F, Chehade S, Lazo-Langner A (2020) Thrombosis risk associated with COVID-19 infection A scoping review. Thromb Res 192:152-160. https://doi.org/10.1016/j.throm res.2020.05.039

61. Bruggemann R, Gietema H, Jallah B, Ten Cate H, Stehouwer C, Spaetgens B (2020) Arterial and venous thromboembolic disease in a patient with COVID-19: a case report. Thromb Res 191:153-155. https://doi.org/10.1016/j.thromres.2020.04.046

62. Valderrama EV, Humbert K, Lord A, Frontera J, Yaghi S (2020) Severe acute respiratory syndrome coronavirus 2 infection and ischemic stroke. Stroke 51(7):e124-e127. https://doi. org/10.1161/STROKEAHA.120.030153

63. Klok FA, Kruip M, van der Meer NJM, Arbous MS, Gommers D, Kant KM, Kaptein FHJ, van Paassen J, Stals MAM, Huisman MV, Endeman H (2020) Confirmation of the high cumulative incidence of thrombotic complications in critically ill ICU patients with COVID-19: an updated analysis. Thromb Res 191:148-150. https://doi.org/10.1016/j.thromres.2020.04.041

64. Tunc A, Unlubas Y, Alemdar M, Akyuz E (2020) Coexistence of COVID-19 and acute ischemic stroke report of four cases. J Clin Neurosci. https://doi.org/10.1016/j.jocn.2020.05.018

65. Escalard S, Chalumeau V, Escalard C, Redjem H, Delvoye F, Hebert S, Smajda S, Ciccio G, Desilles JP, Mazighi M, Blanc R, Maier B, Piotin M (2020) Early brain imaging shows increased severity of acute ischemic strokes with large vessel occlusion in COVID-19 patients. Stroke. https://doi.org/10.1161/STROK EAHA.120.031011

66. Jain R, Young M, Dogra S, Kennedy H, Nguyen V, Jones S, Bilaloglu S, Hochman K, Raz E, Galetta S, Horwtiz L (2020) COVID-19 related neuroimaging findings: a signal of thromboembolic complications and a strong prognostic marker of 
poor patient outcome. J Neurol Sci 414:116923. https://doi. org/10.1016/j.jns.2020.116923

67. Zayet S, Klopfenstein T, Kovacs R, Stancescu S, Hagenkotter B (2020) Acute cerebral stroke with multiple infarctions and COVID-19, France, 2020. Emerg Infect Dis. https://doi. org/10.3201/eid2609.201791

68. Rigamonti A, Mantero V, Piamarta F, Spena G, Salmaggi A (2020) Cerebral venous thrombosis associated with coronavirus infection: an underestimated entity? Neurol Sci. https://doi. org/10.1007/s10072-020-04539-7

69. Chougar L, Mathon B, Weiss N, Degos V, Shor N (2020) Atypical deep cerebral vein thrombosis with hemorrhagic venous infarction in a patient positive for COVID-19. AJNR Am J Neuroradiol 41(8):1377-1379. https://doi.org/10.3174/ajnr.A6642

70. Klein DE, Libman R, Kirsch C, Arora R (2020) Cerebral venous thrombosis: a typical presentation of COVID-19 in the young. J Stroke Cerebrovasc Dis. https://doi.org/10.1016/j.jstrokecerebrov asdis.2020.104989

71. Shakibajahromi B, Borhani-Haghighi A, Haseli S, Mowla A (2020) Cerebral venous sinus thrombosis might be under-diagnosed in the COVID-19 era. eNeurologicalSci 20:100256. https ://doi.org/10.1016/j.ensci.2020.100256

72. Saposnik G, Barinagarrementeria F, Brown RD Jr, Bushnell CD, Cucchiara B, Cushman M, deVeber G, Ferro JM, Tsai FY, American Heart Association Stroke C, the Council on E, Prevention (2011) Diagnosis and management of cerebral venous thrombosis: a statement for healthcare professionals from the American Heart Association/American Stroke Association. Stroke 42(4):1158-1192. https://doi.org/10.1161/STR.0b013 e31820a8364

73. Kow CS, Zaihan AF, Hasan SS (2020) Anticoagulant approach in COVID-19 patients with cerebral venous thrombosis. J Stroke Cerebrovasc Dis. https://doi.org/10.1016/j.jstrokecerebrovasdis .2020 .105222

74. Thachil J, Tang N, Gando S, Falanga A, Cattaneo M, Levi M, Clark C, Iba T (2020) ISTH interim guidance on recognition and management of coagulopathy in COVID-19. J Thromb Haemost 18(5):1023-1026. https://doi.org/10.1111/jth.14810

75. Lyons S, O'Kelly B, Woods S, Rowan C, Brady D, Sheehan G, Smyth S (2020) Seizure with CSF lymphocytosis as a presenting feature of COVID-19 in an otherwise healthy young man. Seizure 80:113-114. https://doi.org/10.1016/j.seizure.2020.06.010

76. Elgamasy S, Kamel MG, Ghozy S, Khalil A, Morra ME, Islam SMS (2020) First case of focal epilepsy associated with SARScoronavirus-2. J Med Virol. https://doi.org/10.1002/jmv.26113

77. Sohal S, Mansur M (2020) COVID-19 presenting with seizures. IDCases 20:e00782. https://doi.org/10.1016/j.idcr.2020.e00782

78. Abdulsalam MA, Abdulsalam AJ, Shehab D (2020) Generalized status epilepticus as a possible manifestation of COVID-19. Acta Neurol Scand. https://doi.org/10.1111/ane.13321

79. Somani S, Pati S, Gaston T, Chitlangia A, Agnihotri S (2020) De novo status epilepticus in patients with COVID-19. Ann Clin Transl Neurol 7(7):1240-1244. https://doi.org/10.1002/ acn3.51071

80. Asadi-Pooya AA (2020) Seizures associated with coronavirus infections. Seizure 79:49-52. https://doi.org/10.1016/j.seizu re.2020.05.005

81. Ashraf M, Sajed S (2020) Seizures related to coronavirus disease (COVID-19): case series and literature review. Cureus 12(7):e9378. https://doi.org/10.7759/cureus.9378

82. Vollono C, Rollo E, Romozzi M, Frisullo G, Servidei S, Borghetti A, Calabresi P (2020) Focal status epilepticus as unique clinical feature of COVID-19: a case report. Seizure 78:109-112. https ://doi.org/10.1016/j.seizure.2020.04.009

83. Bhatta S, Sayed A, Ranabhat B, Bhatta RK, Acharya Y (2020) New-onset seizure as the only presentation in a child with
COVID-19. Cureus 12(6):e8820. https://doi.org/10.7759/cureu s. 8820

84. Saeed A, Shorafa E (2020) Status epilepticus as a first presentation of COVID-19 infection in a 3 years old boy Case report and review the literature. IDCases. https://doi.org/10.1016/j. idcr.2020.e00942

85. Hepburn M, Mullaguri N, George P, Hantus S, Punia V, Bhimraj A, Newey CR (2020) Acute symptomatic seizures in critically ill patients with COVID-19: is there an association? Neurocrit Care. https://doi.org/10.1007/s12028-020-01006-1

86. Lu L, Xiong W, Liu D, Liu J, Yang D, Li N, Mu J, Guo J, Li W, Wang G, Gao H, Zhang Y, Lin M, Chen L, Shen S, Zhang H, Sander JW, Luo J, Chen S, Zhou D (2020) New onset acute symptomatic seizure and risk factors in coronavirus disease 2019: a retrospective multicenter study. Epilepsia. https://doi. org/10.1111/epi.16524

87. Duong L, Xu P, Liu A (2020) Meningoencephalitis without respiratory failure in a young female patient with COVID-19 infection in Downtown Los Angeles, early April 2020. Brain Behav Immun. https://doi.org/10.1016/j.bbi.2020.04.024

88. Mardani M, Nadji SA, Sarhangipor KA, Sharifi-Razavi A, Baziboroun M (2020) COVID-19 infection recurrence presenting with meningoencephalitis. New Microbes New Infect 37:100732. https://doi.org/10.1016/j.nmni.2020.100732

89. Bernard-Valnet R, Pizzarotti B, Anichini A, Demars Y, Russo E, Schmidhauser M, Cerutti-Sola J, Rossetti AO, Du Pasquier R (2020) Two patients with acute meningoencephalitis concomitant with SARS-CoV-2 infection. Eur J Neurol. https:// doi.org/10.1111/ene.14298

90. Benameur K, Agarwal A, Auld SC, Butters MP, Webster AS, Ozturk T, Howell JC, Bassit LC, Velasquez A, Schinazi RF, MullinsHu MEWT (2020) Encephalopathy and encephalitis associated with cerebrospinal fluid cytokine alterations and coronavirus disease, Atlanta, Georgia, USA. Emerg Infect Dis 26(9):2016-2021. https://doi.org/10.3201/eid2609.202122

91. Al-Olama M, Rashid A, Garozzo D (2020) COVID-19-associated meningoencephalitis complicated with intracranial hemorrhage: a case report. Acta Neurochir (Wien) 162(7):14951499. https://doi.org/10.1007/s00701-020-04402-w

92. Rahimi K (2020) Guillain-Barre syndrome during COVID-19 pandemic: an overview of the reports. Neurol Sci. https://doi. org/10.1007/s10072-020-04693-y

93. Khalifa M, Zakaria F, Ragab Y, Saad A, Bamaga A, Emad Y, Rasker JJ (2020) Guillain-Barre syndrome associated with SARS-CoV-2 detection and a COVID-19 infection in a Child. J Pediatric Infect Dis Soc. https://doi.org/10.1093/jpids/piaa0 86

94. Berciano J, Gallardo E (2020) Spinal nerve pathology in Guillain-Barre syndrome associated with COVID-19 infection. Muscle Nerve. https://doi.org/10.1002/mus.27031

95. Tiet MY, AlShaikh N (2020) Guillain-Barre syndrome associated with COVID-19 infection: a case from the UK. BMJ Case Rep. https://doi.org/10.1136/bcr-2020-236536

96. Sancho-Saldana A, Lambea-Gil A, Liesa JLC, Caballo MRB, Garay MH, Celada DR, Serrano-Ponz M (2020) Guillain-Barre syndrome associated with leptomeningeal enhancement following SARS-CoV-2 infection. Clin Med (Lond) 20(4):e93-e94. https://doi.org/10.7861/clinmed.2020-0213

97. Tatu L, Nono S, Gracio S, Kocer S (2020) Guillain-Barre syndrome in the COVID-19 era: another occasional cluster? J Neurol. https://doi.org/10.1007/s00415-020-10005-3

98. Caress JB, Castoro RJ, Simmons Z, Scelsa SN, Lewis RA, Ahlawat A, Narayanaswami P (2020) COVID-19-associated GuillainBarre syndrome: the early pandemic experience. Muscle Nerve. https://doi.org/10.1002/mus.27024 
99. Lascano AM, Epiney JB, Coen M, Serratrice J, Bernard-Valnet R, Lalive PH, Kuntzer T, Hubers A (2020) SARS-CoV-2 and Guillain-Barre syndrome: AIDP variant with favorable outcome. Eur J Neurol. https://doi.org/10.1111/ene.14368

100. Assini A, Benedetti L, Di Maio S, Schirinzi E, Del Sette M (2020) New clinical manifestation of COVID-19 related Guillain-Barre syndrome highly responsive to intravenous immunoglobulins: two Italian cases. Neurol Sci 41(7):1657-1658. https://doi.org/10.1007/s10072-020-04484-5

101. Ray A (2020) Miller Fisher syndrome and COVID-19: is there a link? BMJ Case Rep. https://doi.org/10.1136/bcr-2020-23641 9

102. Yoshikawa K, Kuwahara M, Morikawa M, Fukumoto Y, Yamana M, Yamagishi Y, Kusunoki S (2018) Varied antibody reactivities and clinical relevance in anti-GQ1b antibody-related diseases. Neurol Neuroimmunol Neuroinflamm 5(6):e501. https://doi. org/10.1212/NXI.0000000000000501

103. Fernandez-Dominguez J, Ameijide-Sanluis E, Garcia-Cabo C, Garcia-Rodriguez R, Mateos V (2020) Miller-Fisher-like syndrome related to SARS-CoV-2 infection (COVID 19). J Neurol. https://doi.org/10.1007/s00415-020-09912-2

104. Abu-Rumeileh S, Abdelhak A, Foschi M, Tumani H, Otto M (2020) Guillain-Barre syndrome spectrum associated with COVID-19: an up-to-date systematic review of 73 cases. J Neurol. https://doi.org/10.1007/s00415-020-10124-x

105. de Silva NL, Weeratunga P, Umapathi T, Malavige N, Chang T (2019) Miller Fisher syndrome developing as a parainfectious manifestation of dengue fever: a case report and review of the literature. J Med Case Rep 13(1):120. https://doi.org/10.1186/ s13256-019-2066-z

106. Lantos JE, Strauss SB, Lin E (2020) COVID-19-associated Miller Fisher syndrome: MRI findings. AJNR Am J Neuroradiol 41(7):1184-1186. https://doi.org/10.3174/ajnr.A6609

107. Zachariadis A, Tulbu A, Strambo D, Dumoulin A, Di Virgilio G (2020) Transverse myelitis related to COVID-19 infection. J Neurol. https://doi.org/10.1007/s00415-020-09997-9

108. Chakraborty U, Chandra A, Ray AK, Biswas P (2020) COVID19-associated acute transverse myelitis: a rare entity. BMJ Case Rep. https://doi.org/10.1136/bcr-2020-238668

109. AlKetbi R, AlNuaimi D, AlMulla M, AlTalai N, Samir M, Kumar $\mathrm{N}$ (2020) Acute myelitis as a neurological complication of covid19: a case report and mri findings. Radiol Case Rep. https://doi. org/10.1016/j.radcr.2020.06.001

110. Sotoca J, Rodriguez-Alvarez Y (2020) COVID-19-associated acute necrotizing myelitis. Neurol Neuroimmunol Neuroinflamm. https://doi.org/10.1212/NXI.0000000000000803

111. Chow CCN, Magnussen J, Ip J, Su Y (2020) Acute transverse myelitis in COVID-19 infection. BMJ Case Rep. https://doi. org/10.1136/bcr-2020-236720

112. Princiotta Cariddi L, Tabaee Damavandi P, Carimati F, Banfi P, Clemenzi A, Marelli M, Giorgianni A, Vinacci G, Mauri M, Versino M (2020) Reversible encephalopathy syndrome (PRES) in a COVID-19 patient. J Neurol 267(11):3157-3160. https://doi. org/10.1007/s00415-020-10001-7

113. Anderson RC, Patel V, Sheikh-Bahaei N, Liu CSJ, Rajamohan AG, Shiroishi MS, Kim PE, Go JL, Lerner A, Acharya J (2020) Posterior reversible encephalopathy syndrome (PRES): pathophysiology and neuro-imaging. Front Neurol 11:463. https://doi. org/10.3389/fneur.2020.00463

114. Franceschi AM, Ahmed O, Giliberto L, Castillo M (2020) Hemorrhagic posterior reversible encephalopathy syndrome as a manifestation of COVID-19 infection. AJNR Am J Neuroradiol 41(7):1173-1176. https://doi.org/10.3174/ajnr.A6595

115. Dias DA, de Brito LA, Neves LO, Paiva RGS, Barbosa Junior OA, Tavares-Junior JWL (2020) Hemorrhagic PRES: an unusual neurologic manifestation in two COVID-19 patients. Arq
Neuropsiquiatr 78(11):739-740. https://doi.org/10.1590/0004282X20200184

116. Kishfy L, Casasola M, Banankhah P, Parvez A, Jan YJ, Shenoy AM, Thomson C, AbdelRazek MA (2020) Posterior reversible encephalopathy syndrome (PRES) as a neurological association in severe Covid-19. J Neurol Sci 414:116943. https://doi. org/10.1016/j.jns.2020.116943

117. Ellul MA, Benjamin L, Singh B, Lant S, Michael BD, Easton A, Kneen R, Defres S, Sejvar J, Solomon T (2020) Neurological associations of COVID-19. Lancet Neurol 19(9):767-783. https ://doi.org/10.1016/s1474-4422(20)30221-0

118. Llorente Ayuso L, Torres Rubio P, Beijinho do Rosario RF, Giganto Arroyo ML, Sierra-Hidalgo F (2020) Bickerstaff encephalitis after COVID-19. J Neurol. https://doi.org/10.1007/ s00415-020-10201-1

119. Collantes MEV, Espiritu AI, Sy MCC, Anlacan VMM, Jamora RDG (2020) Neurological manifestations in COVID-19 infection: a systematic review and meta-analysis. Can J Neurol Sci. https://doi.org/10.1017/cjn.2020.146

120. Aksan F, Nelson EA, Swedish KA (2020) A COVID-19 patient with intense burning pain. J Neurovirol. https://doi.org/10.1007/ s13365-020-00887-4

121. Balestrino R, Rizzone M, Zibetti M, Romagnolo A, Artusi CA, Montanaro E, Lopiano L (2020) Onset of Covid-19 with impaired consciousness and ataxia: a case report. J Neurol. https ://doi.org/10.1007/s00415-020-09879-0

122. Diezma-Martín MI, García-Alvarado N, Vadillo BA, LópezAriztegui N, Sepúlveda BMA (2020) Tremor and ataxia in COVID-19. Neuralgia Barc Spain. https://doi.org/10.1016/j. nrl.2020.06.005

123. Poyiadji N, Shahin G, Noujaim D, Stone M, Patel S, Griffith B (2020) COVID-19-associated acute hemorrhagic necrotizing encephalopathy: imaging features. Radiology 296(2):E119E120. https://doi.org/10.1148/radiol.2020201187

124. Ghosh R, Dubey S, Finsterer J, Chatterjee S, Ray BK (2020) SARS-CoV-2-associated acute hemorrhagic, necrotizing encephalitis (AHNE) presenting with cognitive impairment in a 44-yearold woman without comorbidities: a case report. Am J Case Rep 21:e925641. https://doi.org/10.12659/AJCR.925641

125. Anand P, Zakaria A, Benameur K, Ong C, Putman M, O'Shea S, Greer D, Cervantes-Arslanian AM (2020) Myoclonus in patients with coronavirus disease 2019: a multicenter case series. Crit Care Med. https://doi.org/10.1097/CCM.0000000000004570

126. Rabano-Suarez P, Bermejo-Guerrero L, Mendez-Guerrero A, Parra-Serrano J, Toledo-Alfocea D, Sanchez-Tejerina D, Santos-Fernandez T, Folgueira-Lopez MD, Gutierrez-Gutierrez J, Ayuso-Garcia B, Gonzalez de la Aleja J, Benito-Leon J (2020) Generalized myoclonus in COVID-19. Neurology 95(6):e767e772. https://doi.org/10.1212/WNL.0000000000009829

127. Reichard RR, Kashani KB, Boire NA, Constantopoulos E, Guo Y, Lucchinetti CF (2020) Neuropathology of COVID-19: a spectrum of vascular and acute disseminated encephalomyelitis (ADEM)-like pathology. Acta Neuropathol. https://doi. org/10.1007/s00401-020-02166-2

128. Novi G, Rossi T, Pedemonte E, Saitta L, Rolla C, Roccatagliata L, Inglese M, Farinini D (2020) Acute disseminated encephalomyelitis after SARS-CoV-2 infection. Neurol Neuroimmunol Neuroinflamm. https://doi.org/10.1212/NXI.0000000000000797

129. Dinkin M, Gao V, Kahan J, Bobker S, Simonetto M, Wechsler P, Harpe J, Greer C, Mints G, Salama G, Tsiouris AJ, Leifer D (2020) COVID-19 presenting with ophthalmoparesis from cranial nerve palsy. Neurology 95(5):221-223. https://doi. org/10.1212/WNL.0000000000009700

130. Radmanesh A, Derman A, Ishida K (2020) COVID-19-associated delayed posthypoxic necrotizing leukoencephalopathy. J Neurol Sci 415:116945. https://doi.org/10.1016/j.jns.2020.116945 
131. Kaya Y, Kara S, Akinci C, Kocaman AS (2020) Transient cortical blindness in COVID-19 pneumonia; a PRES-like syndrome: case report. J Neurol Sci 413:116858. https://doi.org/10.1016/j. jns. 2020.116858

132. Fadakar N, Ghaemmaghami S, Masoompour SM, Shirazi Yeganeh B, Akbari A, Hooshmandi S, Ostovan VR (2020) A first case of acute cerebellitis associated with coronavirus disease (covid-19): a case report and literature review. Cerebellum. https ://doi.org/10.1007/s12311-020-01177-9

133. Bösel J, Berlit P (2020) Neurologische auswirkungen von COVID-19. DGNeurologie. https://doi.org/10.1007/s42451-02000191-9

134. Cuhna P, Herlin B, Vassilev K, Kas A, Lehericy S, Worbe Y, Apartis E, Vidailhet M, Dupont S (2020) Movement disorders as a new neurological clinical picture in severe SARS-CoV-2 infection. Eur J Neurol. https://doi.org/10.1111/ene.14474

135. Ardila A, Lahiri D (2020) Executive dysfunction in COVID-19 patients. Diabetes Metab Syndr 14(5):1377-1378. https://doi. org/10.1016/j.dsx.2020.07.032

136. Dugue R, Cay-Martinez KC, Thakur KT, Garcia JA, Chauhan LV, Williams SH, Briese T, Jain K, Foca M, McBrian DK, Bain
JM, Lipkin WI, Mishra N (2020) Neurologic manifestations in an infant with COVID-19. Neurology 94(24):1100-1102. https ://doi.org/10.1212/WNL.0000000000009653

137. Jin M, Tong Q (2020) Rhabdomyolysis as potential late complication associated with COVID-19. Emerg Infect Dis 26(7):16181620. https://doi.org/10.3201/eid2607.200445

138. Bagnato S, Boccagni C, Marino G, Prestandrea C, D’Agostino T, Rubino F (2020) Critical illness myopathy after COVID-19. Int J Infect Dis 99:276-278. https://doi.org/10.1016/j.jiid.2020.07.072

139. Tankisi H, Tankisi A, Harbo T, Markvardsen LK, Andersen H, Pedersen TH (2020) Critical illness myopathy as a consequence of Covid-19 infection. Clin Neurophysiol 131(8):1931-1932. https://doi.org/10.1016/j.clinph.2020.06.003

140. Dalakas MC (2020) Guillain-Barre syndrome: the first documented COVID-19-triggered autoimmune neurologic disease: more to come with myositis in the offing. Neurol Neuroimmunol Neuroinflamm. https://doi.org/10.1212/NXI.0000000000000781

141. Azouz E, Yang S, Monnier-Cholley L, Arrive L (2020) Systemic arterial thrombosis and acute mesenteric ischemia in a patient with COVID-19. Intensive Care Med 46(7):1464-1465. https:// doi.org/10.1007/s00134-020-06079-2 